\title{
Effect of Salinity on Germination and Root Growth of Jordanian Barley
}

\author{
Ayah Awad', Nidal Odat ${ }^{2}$, Saeid Abu-Romman', Maen Hasan³, \\ Abdel Rahman Al-Tawaha ${ }^{4}$ \\ 1 Department of Biotechnology, Al-Balqa Applied University, Al-Salt 19117, Jordan \\ 2 Department of Medical Laboratories, Al-Balqa Applied University, Al-Salt 19117, Jordan \\ 3 Department of Plant Production and Protection, Al-Balqa Applied University, Al-Salt 19117, Jordan \\ 4 Department of Biological Sciences, Al-Hussein Bin Talal University, Maan 71111, Jordan \\ * Corresponding author's e-mail: abdel-al-tawaha@ahu.edu.jo
}

\begin{abstract}
The fundamental aim of this study was to investigate the growth responses of selected Jordanian cultivated barley (Hordeum vulgare L.) genotypes to the salinity stress. Twenty-six landraces and two recent cultivars were subjected to four levels of salinity $(0,50,100$ and $200 \mathrm{mM} \mathrm{NaCl})$. The salt stress was found to influence the majority of germination ability such as germination $\%$ which ranged from about $80 \%$ to $100 \%$ (One-way ANOVA; $p \leq 0.05$ ). Moreover, germination was statistically affected in correspondence to exposure time to salinity and in relation to genotypic composition of studied barley (two-row vs. six-row accessions) (Two-Way ANOVA; $p \leq 0.05$ ). Early seedling growth traits were also found to decline with increasing salinity stress. Moreover, according to the growth parameters genotypes, M’1595, M'1593, Ir 1558, Ir 1631, Ir 1639, Mf 1545, and Mf 1548 were found to have better performance than others. On the other hand, the genotypes M'1593, M'1594, M'1595, Ir 1558, Ra 1552, Ra 1611, Mf 1616, Mf 1617, and Ma 1592 were most affected genotypes by salinity. The results of this study lead to the conclusion that the response to the salinity stress is complex, yet the comprehensive results found in this study provide a foundation for deeper exploration of diversity as well as the gene-trait relationships and their utilization in future barley improvement.
\end{abstract}

Keywords: salinity stress, barley, germination, landraces, cultivars.

\section{INTRODUCTION}

The salt stress has become an important problem regarding the agricultural production in many regions of the world [Shrivastava \& Kumar, 2014]. It is estimated that more than 60 million hectares of irrigated land, representing some $25 \%$ of the total irrigated land, have been damaged by the salt stress [Mekhaldi et al., 2008]. The salt stress causes a great reduction in the plant growth and biomass production of cereal plants such as barley, wheat and rice [Flowers and Yeo 1995]. Human activities like poor management of water and soil, and over irrigation of poorly drained soils are also responsible for the soil salinity [Anwar et al., 2011] High soil salinity is among the most widespread abiotic stress factor limiting the plant distribution and productivity. The salinity stress plays a major role in decreasing the global crop productivity [Ashraf and Foolad, 2007]. Land irrigation with saline water is a key factor that lead to salt accumulation in soil thus has a profound effect on agriculture [Shrivastava and Kumar, 2015]. Moreover, the expected increase in secondary salinization due to the extension of agriculture to semi-arid and arid regions, intense irrigation, change in the global climate, and overpopulation will lead to the harmful effects on agricultural systems. Additionally, the hydrologic balance caused by soil salinity together with increasing demand on water because of overpopulation will lead to limited 
agricultural potential [Passioura, 2007]. The most common salt in soils is sodium chloride $(\mathrm{NaCl})$, which recently showed a momentum in research and crop management decision. The over-accumulation of $\mathrm{NaCl}$ limits the plant growth and the biomass production as a result of the ion toxicity and decreased water uptake [Yadav et al., 2010]. Moreover, the salinity stress adversely affects different stages of growth and development, such as germination, early seedling establishment, vegetative growth, flowering and fruit set [Anwar et al., 2011]. The germination potential of plants is reduced by many stress factors such as the salt and drought stresses which are considered among the most important abiotic factors that delay germination (Ansari et al., 2013). Moreover, the salt stress has various negative effects on germination such as decrease in the germination percentage and limited seedling growth [Qiu, et al., 2011]. Seed germination is associated with a complex physiological process triggered by imbibition of water after possible dormancy that followed by the emergence of radicle [Ansari et al., 2013]. Moreover, the germination rate depends largely on the genetic and environmental factors, such as temperature, light, and salinity [Barbour, 1988]. Seed germination is considered the most sensitive and critical stage to the abiotic stress [Patade et al., 2011]. High intracellular concentrations of both $\mathrm{Na}^{+}$and $\mathrm{Cl}^{-}$can inhibit the metabolism of dividing and expanding cells thus, inhibit the germination potential and in some cases lead to seed death. These effects indirectly influence the photosynthetic process, as it leads to the chemical disturbances of necessary biochemical reactions of plant cells [Hasanuzzaman et al., 2013]. Barley is a vital crop worldwide after maize, wheat, and rice. In the arid and semi-arid areas of Jordan, barley is the used as feed for livestock and for small ruminants, whereas both the grain and straw are utilized. Jordan is regarded as important hotspot for barley genetic variations. The arid and semiarid regions of the Jordan ecosystem are significantly influenced by the soil salinity because of limited rainfall, high evapotranspiration and high temperature [Abdel-Ghani 2009]. Barley is considered among the most planted cereal crops in Jordan and other Mediterranean countries. Barley is mostly cultivated in the arid and semi-arid regions (200-330 $\mathrm{mm}$ rainfall per year). The decrease of the barley yields in Jordan is caused by the variable and irregular distribution of rainfall. In general, there are several factors affecting the barley growth and production: salinity, water supply, soil fertility, weed competition, insects and diseases [Brigges, 1978]. The selection process of barley by humans during domestication leads to the emergence of two different phenotypes or morphs, namely six-rowed barley or (Hordeum vulgare L. hexastichum) two-rowed barley (Hordeum vulgare L. distichum), which show different genetic diversity [Odat et al., 2015]. Besides its agronomic and economic importance, barley is considered an efficient plant for the genetic effect of stress factors such as salinity.

\section{MATERIALS AND METHODS}

\section{Source of seeds and experimental setup}

Twenty-eight different genetically local samples of Jordanian barley (Hordeum vulgare L.) were used in the present study. The barley samples correspond to two sets of gene pools (sixrowed spike and two-rowed spike), and one set of recent cultivars of barley. The seeds were obtained from the National Center for Agricultural Research and Extension (NCARE), Jordan. These seeds were originally collected from various locations of Jordan. The seeds chosen for this study are of various genetic diversity and domestication history [Odat et al., 2015]. The barley genotypes, their collection sites, and their genome types are listed in (Table 1). The experiments in this study were conducted under laboratory conditions.

\section{Effects of $\mathrm{NaCl}$ salinity on seed germination}

A sample of 120 barley seeds with almost equal weight from the studied barley samples were first surface-sterilized using sodium hypochlorite $(1.0 \%)$ for 5 minutes, followed by washing twice with distilled water and then drying at room temperature. Ten seeds per replicate of every barley genotypes for the four levels of $\mathrm{NaCl}$ were placed in Petri dishes lined with a towel paper and a filter paper containing $20 \mathrm{ml}$ of $\mathrm{NaCl}$ solutions at three concentrations $(50,100,200 \mathrm{mM})$, and dd $\mathrm{H}_{2} \mathrm{O}$ water as a control. The dishes were then placed in the dark under growth chamber at $23^{\circ} \mathrm{C}$ in a block design (randomized). The seeds were immersed with distilled water or $\mathrm{NaCl}$ solutions, and germination was scored on day 4, 6 and 8 . The seeds were evaluated for germinated after the appearance of the radicle of at approximately $3 \mathrm{~mm}$ in 
Table 1. Barley genotypes used in this study, their collection, sites and dates and row types the seeds

\begin{tabular}{|c|c|c|c|c|}
\hline GeneBank Accession Number & Row type & ICARDA collection date & Location & Altitude $(\mathrm{m})$ \\
\hline 1560 & 6 & $1981 / 05 / 24$ & Zarqa & 550 \\
\hline 1622 & 6 & $1981 / 05 / 20$ & Zarqa & 600 \\
\hline 1594 & 6 & $1985 / 05 / 19$ & Ma'an & 1450 \\
\hline 1645 & 6 & $1991 / 05 / 23$ & Mafraq & 670 \\
\hline 1553 & 6 & $1981 / 05 / 22$ & Irbid & 450 \\
\hline 1555 & 6 & $1981 / 05 / 22$ & Irbid & 500 \\
\hline 1621 & 6 & $1988 / 05 / 25$ & Irbid & 340 \\
\hline 1634 & 6 & $1991 / 05 / 20$ & Irbid & 300 \\
\hline 1636 & 6 & $1991 / 05 / 20$ & Irbid & 325 \\
\hline 1639 & 6 & $1991 / 05 / 20$ & Irbid & 510 \\
\hline 1580 & 2 & $1981 / 06 / 02$ & Ma'an & 1500 \\
\hline 1593 & 2 & $1985 / 05 / 18$ & Ma'an & 1500 \\
\hline 1595 & 2 & $1985 / 05 / 19$ & Ma'an & 1450 \\
\hline 1548 & 2 & $1981 / 05 / 20$ & Mafraq & 700 \\
\hline 1616 & 2 & $1985 / 05 / 21$ & Mafraq & 710 \\
\hline 1617 & 2 & $1985 / 05 / 21$ & Mafraq & 710 \\
\hline 1631 & 2 & $1991 / 05 / 18$ & Irbid & 800 \\
\hline 1558 & 2 & $1981 / 05 / 23$ & Irbid & -200 \\
\hline 1572 & 2 & $1981 / 05 / 28$ & Tafila & 850 \\
\hline 1599 & 2 & $1985 / 05 / 19$ & Tafila & 1300 \\
\hline 1592 & 2 & $1985 / 05 / 18$ & Madaba & 710 \\
\hline 1618 & 2 & $1985 / 05 / 22$ & Madaba & 760 \\
\hline 1552 & 2 & $1981 / 05 / 21$ & Irbid & 460 \\
\hline 1611 & 2 & $1985 / 05 / 21$ & Irbid & 550 \\
\hline 1659 & 2 & $1991 / 05 / 29$ & Karak & 890 \\
\hline 1658 & 2 & $1991 / 05 / 28$ & Karak & 1220 \\
\hline
\end{tabular}

length [Adjel et al., 2013]. At each time interval, the following measurements (growth traits) were taken: number of roots, total roots length, maximum root length, seminal root number, coleoptile length, speed of germination, growth rate and germination percentage. The germination \% was estimated using the formula: $\mathrm{G} \%=(\mathrm{GS} / \mathrm{TS}) \mathrm{X}$ 100 , where GS is the number of germinated barley and TS represents total seeds used (Adjel et al., 2013). The rate of barley germination was evaluated according to the modified Timson's index using the equation: $(\Sigma G / t$.

\section{Statistical analysis}

All data were log transformed, when necessary, before a statistical analysis was performed. The estimated values of the studied parameters were presented first using univariate descriptive statistics. The comparisons of the studied parameters were conducted by the SPSS package (SPSS Inc. 1994). One and two-way ANOVA were estimated to evaluate the effect of salt stress, all duration of stress, the genome types and their combination on the studied characteristics of barley.

\section{RESULTS}

\section{Germination characteristics}

The germination experiments investigated in this study provided interesting results on a varied range of genotypes that have been studied. The salt stress was found to influence the majority of germination characteristics. The results showed that the germination percentage decreased at different levels of salinity $(50 \mathrm{mM}$ and $100 \mathrm{mM}$ of $\mathrm{NaCl}$ ). However, at lower and moderate levels of salt stress, i.e. $50 \mathrm{mM}$ and 100 , the germination percentage ranged from $80 \%$ to $100 \%$, while at higher levels, i.e. $200 \mathrm{mM}$, the percentage ranged from $60 \%$ to $80 \%$. However, at the higher of $200 \mathrm{mM}$ of $\mathrm{NaCl}$, the germination percentage increased along with the exposure time to the salinity stress. Additionally, it was found that the germination rate accelerated from 26.1 to 
33 between day 4 and 6 , whereas the maximum accelerated germination rate reported to be 20.4 to 66.67 in the interval time of exposure between day six and eight. The germination rate was found to be reduced mostly at a concentration of 200 $\mathrm{mM}$ during the exposure time from day four until day eight (Table 2). Specifically, the results indicated that genotypes from Mafraq (Mf 1617), Tafeliah (Ta 1572), Irbid (Ir 1639, Ir 1634), (Za 1622), and Ma'an (M'1595) have the highest germination percentage at all levels of $\mathrm{NaCl}$, i.e. 50 $\mathrm{mM}, 100 \mathrm{mM}$, and $200 \mathrm{mM}$ at almost all the germination period. On the other hand, the genotype from Karak (Ka 1659) and one of the cultivars (Mutah) had higher percentage of germination at day 4 and 8 under $50 \mathrm{mM}$ and $100 \mathrm{mM}$ only (Table 1). However, the genotypes that had low germination percentage at day 4, 6 and 8 under $200 \mathrm{mM}$ were the two cultivars of Rum, Mutah and $\mathrm{Ra} 1611$.

\section{Germinating seedlings characteristics}

Different growth characteristics, i.e. number of roots, seminal root number, the total roots length, maximum root length, and coleoptile length, have been measured in this study. The combined effect of salinity, exposure time, and their interaction (Salinity $\times$ Time) were found to show significant effects. The range of root number was between 3.58 and 5.69 of germinated seeds in response to the different $\mathrm{NaCl}$ level at different time of intervals, with a noticeable decrease at high salinity of $\mathrm{NaCl}(200 \mathrm{mM})$ (Figure 1).

The total number of roots of the germinated seeds was measured along the germination period, and the results showed that some of the genotypes have the lowest number of roots e.g. Ka 1659 and Mutah. Rum and (Ra 1611) have no roots germinated along the germination period under 200 $\mathrm{mM}$, compared to those that have significantly high number of roots like Ma 1592, Mf 1616 at day 4 under 50 and $100 \mathrm{mM}$. However, on day 6 and under $100 \mathrm{mM}$, M' 1580 and M' 1594 have the highest number of roots, but on day 8 , only the genotype (Ir 1631) showed an increase in the roots number under $100 \mathrm{mM}$. Moreover, Ta 1599 showed the highest roots number under $100 \mathrm{mM}$ on day 4, 6 and 8 (Table 3). The seminal roots number ranged from 1 root to 4.5 roots in average per germinated seed. The seminal roots number showed a significant difference under different levels of $\mathrm{NaCl}$ during the treatment period of the

Table 2. Effects of treatment with different concentration of $\mathrm{NaCl}$ on the germination percentage and growth rate

\begin{tabular}{|c|c|c|c|}
\hline & & \multicolumn{2}{|c|}{ Mean \pm Std. error } \\
\hline & & Germination \% & Growth Rate \\
\hline \multirow{7}{*}{4 days after treatment } & 0 & $91.665 \pm 1.343$ & $31.022 \pm 0.401$ \\
\hline & 50 & $87.430 \pm 2.352$ & $29.935 \pm 0.610$ \\
\hline & 100 & $85.578 \pm 1.969$ & $28.920 \pm 0.765$ \\
\hline & 200 & $59.758 \pm 5.213$ & $21.338 \pm 1.704$ \\
\hline & Total & $81.108 \pm 1.936$ & $27.804 \pm 0.612$ \\
\hline & $F$ & 21.783 & 19.219 \\
\hline & $P$ value & 0.000 & 0.000 \\
\hline \multirow{7}{*}{6 days after treatment } & 0 & $94.465 \pm 1.176$ & $31.196 \pm 3.087$ \\
\hline & 50 & $92.178 \pm 1.715$ & $30.681 \pm 3.192$ \\
\hline & 100 & $87.940 \pm 3.331$ & $29.861 \pm 3.232$ \\
\hline & 200 & $68.270 \pm 5.117$ & $19.672 \pm 1.660$ \\
\hline & Total & $85.713 \pm 1.869$ & $27.853 \pm 1.485$ \\
\hline & $F$ & 13.706 & 3.651 \\
\hline & $P$ value & 0.000 & 0.000 \\
\hline \multirow{7}{*}{8 days after treatment } & 0 & $96.667 \pm 1.014$ & $23.542 \pm 0.274$ \\
\hline & 50 & $94.345 \pm 1.423$ & $22.722 \pm 0.422$ \\
\hline & 100 & $92.618 \pm 1.602$ & $22.275 \pm 0.416$ \\
\hline & 200 & $71.547 \pm 5.196$ & $16.413 \pm 1.281$ \\
\hline & Total & $88.794 \pm 1.702$ & $21.238 \pm 0.444$ \\
\hline & $F$ & 16.552 & 20.542 \\
\hline & $P$ value & 0.000 & 0.000 \\
\hline
\end{tabular}

Values means of three replicates with 10 seeds per replicate. 
experiment. On day 8 , the seminal roots number is higher than that on day 6 or 8 (Figure 2).

In total, the varied genotypes of barley have at least 1-2 seminal roots per seed at high $\mathrm{NaCl}$ levels (100 mM, $200 \mathrm{mM}$ ) along the germination period. The genotype Mf 1548 and $\mathrm{Za} 1560$ have the largest number of seminal roots under 100 $\mathrm{mM}$ and $200 \mathrm{mM}$, respectively on day 4 , beside the genotype Irbid (Ir 1631) under $100 \mathrm{mM}$. Under 50 and $100 \mathrm{mM} \mathrm{NaCl}, \mathrm{M}^{\prime} 1580$ scored the highest seminal root number along the three interval times. Unlike a genotype from Ramtha ( $\mathrm{Ra}$ 1611) which showed a reduction in the seminal root number on day 4 under $50 \mathrm{mM}$ and $100 \mathrm{mM}$, (M' 1595) had low seminal root number under $100 \mathrm{mM}$ and $200 \mathrm{mM}$, while the most affected genotypes to $200 \mathrm{mM}$ of $\mathrm{NaCl}$ were (Ka 1659, Ka 1658, Ir 1558, M' 1594, Mutah and Rum) on day 4, but on day 6 and 8 the genotypes from (M' 1595, Mf 1548) and the cultivars (Mutah and
Rum) have the lowest seminal root number at high level of $\mathrm{NaCl}$ on all days of the germination period (Table 4).

An increase in the maximum root length with time was found when seeds were treated with the different concentration of $\mathrm{NaCl}$. For example, on day 4 the range of maximum root length was $0.5-7.5 \mathrm{~cm}$, on day 6 the range was $0.5-13.5 \mathrm{~cm}$, and on day 8 the ranged was $0.5-17.5$ (Figure 3).

The two cultivars that have been used in this study (Mutah and Rum) were among the most affected genotypes to salinity under $200 \mathrm{mM}$ of $\mathrm{NaCl}$. On the other hand, three genotypes ( $\mathrm{M}^{\prime}$ 1595, Ra 1552, and Mf 1548) on day 4 under $50 \mathrm{mM}$ of $\mathrm{NaCl}$ showed a considerable increase in the maximum root length and under the same level of $\mathrm{NaCl}$ Mf 1545 had the highest maximum root length, but at the end of the germination period, Rum showed a better growth under 100 $\mathrm{mM}$ of $\mathrm{NaCl}$. Moreover, the results showed that

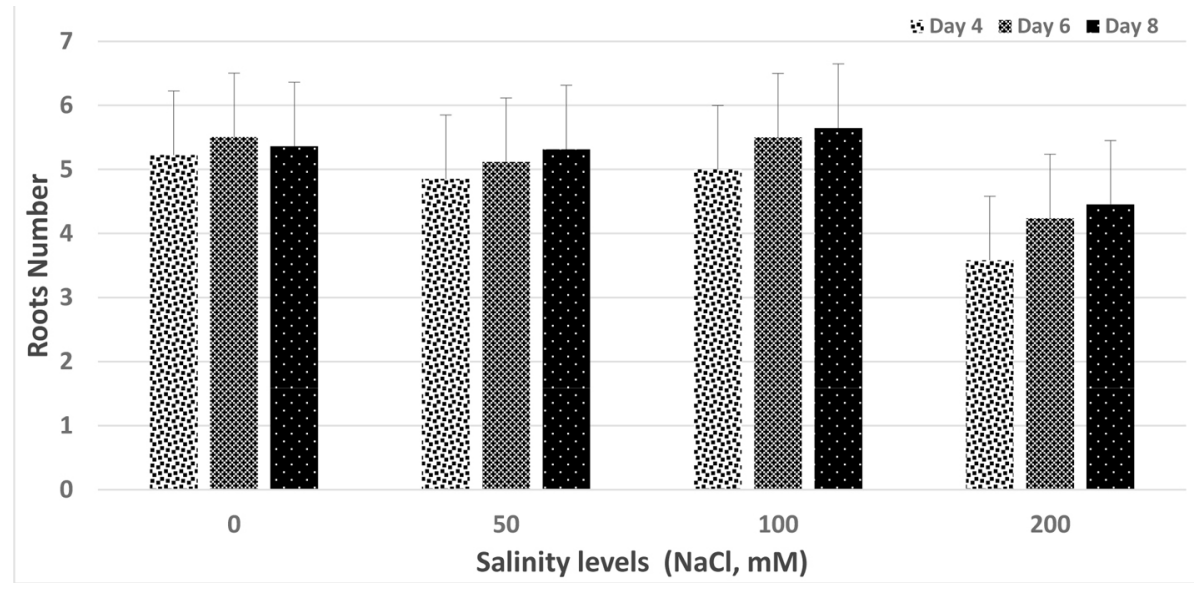

Figure 1. Means of roots number for barley seeds (H. vulgare L.) under different concentrations of $\mathrm{NaCl}(0,50,100$, and $200 \mathrm{mM})$ during different time interval. Bars represent mean $\pm \mathrm{SE}$; $\mathrm{n}=28$ genotypes; 10 seeds/replicate (3 replicates)

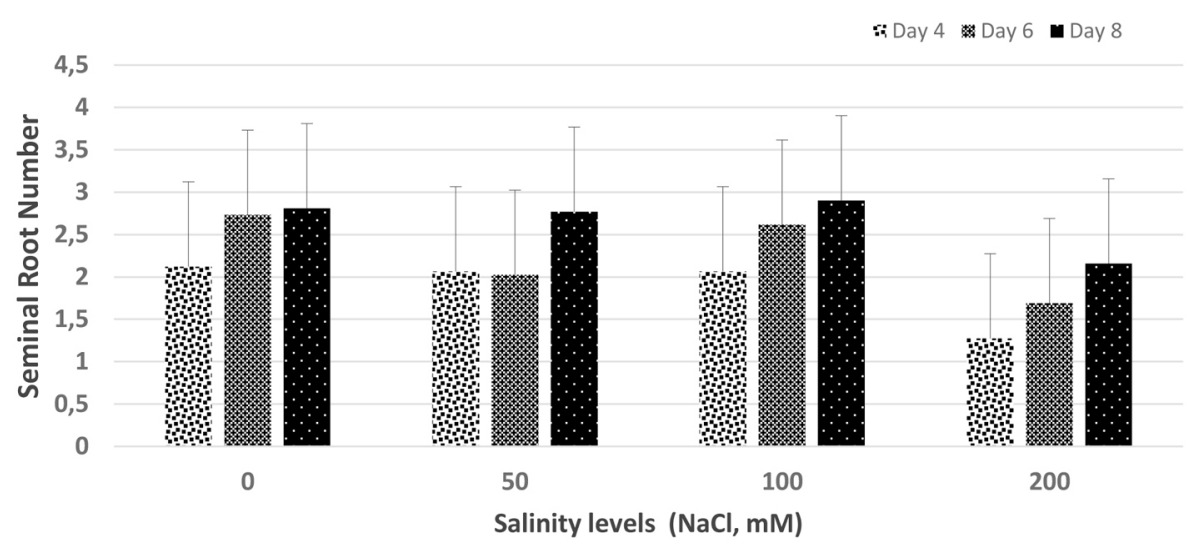

Figure 2. Means of seminal roots number for barley seeds (H. vulgare L.) under different concentrations of $\mathrm{NaCl}(0,50,100$, and $200 \mathrm{mM})$ during different time interval. Bars represent mean $\pm \mathrm{SE}$; $\mathrm{n}=28$ genotypes; 10 seeds/replicate (3 replicates) 
Table 3. Results of two-way analysis of variance (ANOVA) for the effects of salinity, time and their interaction (Salinity $\times$ Time) on germination, growth rate, number of roots, seminal root number, the total roots length, maximum root length, and coleoptile length during the exposure to different levels of $\mathrm{NaCl}$

\begin{tabular}{|l|c|c|c|}
\hline \multicolumn{1}{|c|}{ Dependent Factor } & Salinity & Time & S*T \\
\hline Germination \% & $51.226^{* * * *}$ & $6.378^{* *}$ & 0.313 n.s. \\
\hline Germination Rate & $17.656^{* * * *}$ & $17.816^{* * * *}$ & 0.398 n.s. \\
\hline Roots number & $32.930^{* * * *}$ & $9.325^{* * *}$ & 1.278 n.s. \\
\hline Seminal root number & $20.151^{* * * *}$ & $16.938^{* * * *}$ & $6.927^{* * * *}$ \\
\hline Max root length & $43.738^{* * * *}$ & $160.002^{* * * *}$ & $3.241^{* *}$ \\
\hline Roots length & $41.529^{* * * *}$ & $129.603^{* * * *}$ & $12.628^{* * * *}$ \\
\hline Coleoptile length & $120.585^{* * * *}$ & $187.135^{* * * *}$ & . \\
\hline
\end{tabular}

Factors represent $F$ values: $* P \leq 0.05 ; * * P \leq 0.01 ; * * * P \leq 0.001 ; * * * * P \leq 0.0001$ n.s., non-significant

Table 4. Results of two-way analysis of variance (ANOVA) for the effects of salinity, genotype (6 rowed, two rowed and the two cultivars) and their interaction (Salinity $\times$ Genotype) on germination, growth rate, number of roots, seminal root number, the total roots length, maximum root length, and coleoptile length during the exposure to different levels of $\mathrm{NaCl}$

\begin{tabular}{|l|c|c|c|}
\hline \multicolumn{1}{|c|}{ Dependent Factor } & Salinity & Genotype & S*G \\
\hline Germination \% & $244.477^{* * * *}$ & $18.101^{* * * *}$ & $11.153^{* * * *}$ \\
\hline Germination Rate & $19.106^{* * *}$ & $2.608^{* * * *}$ & $1.201^{* * * *}$ \\
\hline Roots number & $101.783^{* * * *}$ & $10.463^{* * * *}$ & $2.001^{* * * *}$ \\
\hline Seminal root number & $30.868^{* * * *}$ & $6.070^{* * * *}$ & 1.249 n.s. \\
\hline Max root length & $20.101^{* * * *}$ & $1.394^{* * s .}$ & 0.866 n.s. \\
\hline Roots length & $25.781^{* * *}$ & $1.814^{*}$ & 0.665 n.s. \\
\hline Coleoptile length & $46.520^{* * * *}$ & 0.768 n.s. & n. \\
\hline
\end{tabular}

Factors represent $F$ values: $* P \leq 0.05 ; * * P \leq 0.01 ; * * * P \leq 0.001 ; * * * * P \leq 0.0001$ n.s., non-significant.

Rum and Mutah have the maximum root length at $50 \mathrm{mM}$ and $100 \mathrm{mM}$ (Table D). Similar to the maximum root length, the total roots length was affected by salinity and the minimum and the maximum values of total roots length ranged from $4.7-12.17 \mathrm{~cm}$ on day 4 , on day 6 it was in the range of $12.5-29.7 \mathrm{~cm}$ and at the end of the period of treatment $-16.5-57.2 \mathrm{~cm}$ (Figure 4).

Rum, Mutah, and Ra 1611 have the smallest total roots length compared to the controls under $200 \mathrm{mM}$, but on the other hand, on day 4 (M' 1595) and under 50 and $200 \mathrm{mM}$ showed an increase in the total roots length, also on day 6 under $200 \mathrm{mM}$ (Ka 1659) have high total roots length, ( $\mathrm{Ra} 1552)$ under $50 \mathrm{mM}$ on both day 4 and day 8 also had a high total roots length. Thus, (M' 1595) had the highest total roots number which consider the most tolerant genotype according to this growth trait.

In general, the statistical analysis demonstrated a significant difference in coleoptile length at all $\mathrm{NaCl}$ levels (Figure 5). The genotypes that have the highest coleoptile length when exposed to $50 \mathrm{mM}$ of $\mathrm{NaCl}$ on day 4 were M' 1595 , Ir 1558 , Mf 1548 , while on day 6 the M' 1593 showed a greater growth under $200 \mathrm{mM}$, and at the end of the germination period on day 8 the genotype, Ir 1631 had the highest coleoptile length (Table 3). The genotypes that have the smallest coleoptile length were (Mf 1548) at $200 \mathrm{mM}$ on all days of the germination period, Ma'an (M'1595), Ramtha (Ra 1552) on day 4 under 200 mM, Irbid (Ir 1558) on day 6 under $200 \mathrm{mM}$, also Mutah, Rum, (Ra 1611), and (M'1595) on day 8 under $200 \mathrm{mM}$. Some of the genotypes (Ma 1618, Ma 1592, Ra 1611, Ir 1639) showed a decrease in the coleoptile length at the beginning of the germination period (at day 4), but at the end of the period, the growth of coleoptile length was enhanced (Table 3 ).

\section{Effect of exposure time of salinity}

The findings of the present work indicated a statistically large variation for the effect of salinity and exposure time. Specifically, two-way analysis of variance (ANOVA) showed significant differences of percentage of germination and germination rate at different levels of $\mathrm{NaCl}$ during the treatment period of the experiment. The results, however, did not show a combined effect of salinity and exposure time (two-way ANOVA; Table 3), The results of the growth parameters 


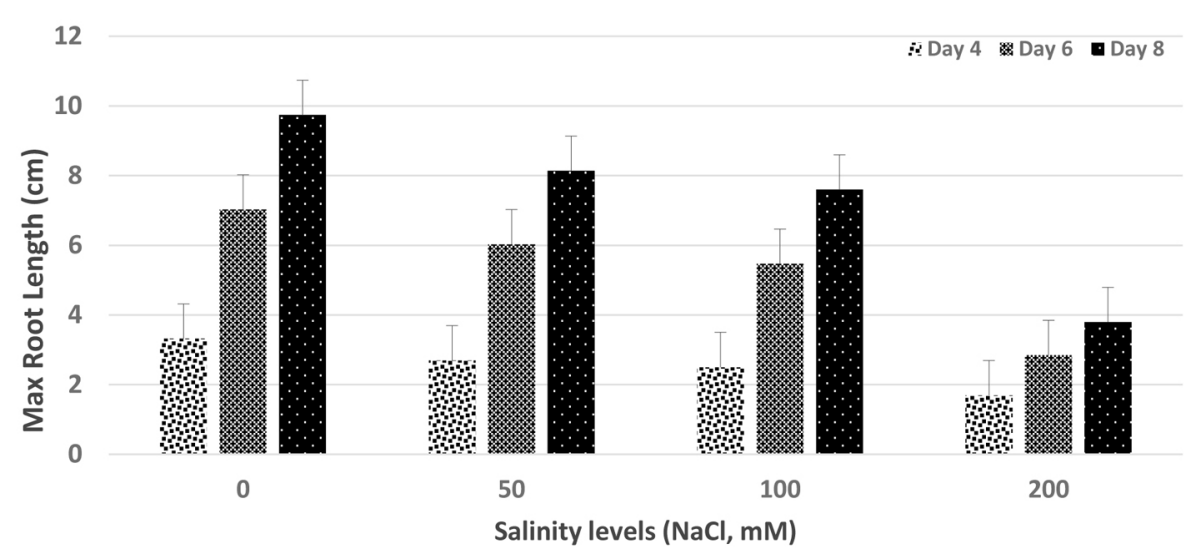

Figure 3. Means of maximum roots length for barley seeds (H. vulgare L.) under different concentrations of $\mathrm{NaCl}(0,50,100$, and $200 \mathrm{mM})$ during different time interval. Bars represent mean $\pm \mathrm{SE} ; \mathrm{n}=28$ genotypes; 10 seeds/replicate (3 replicates)

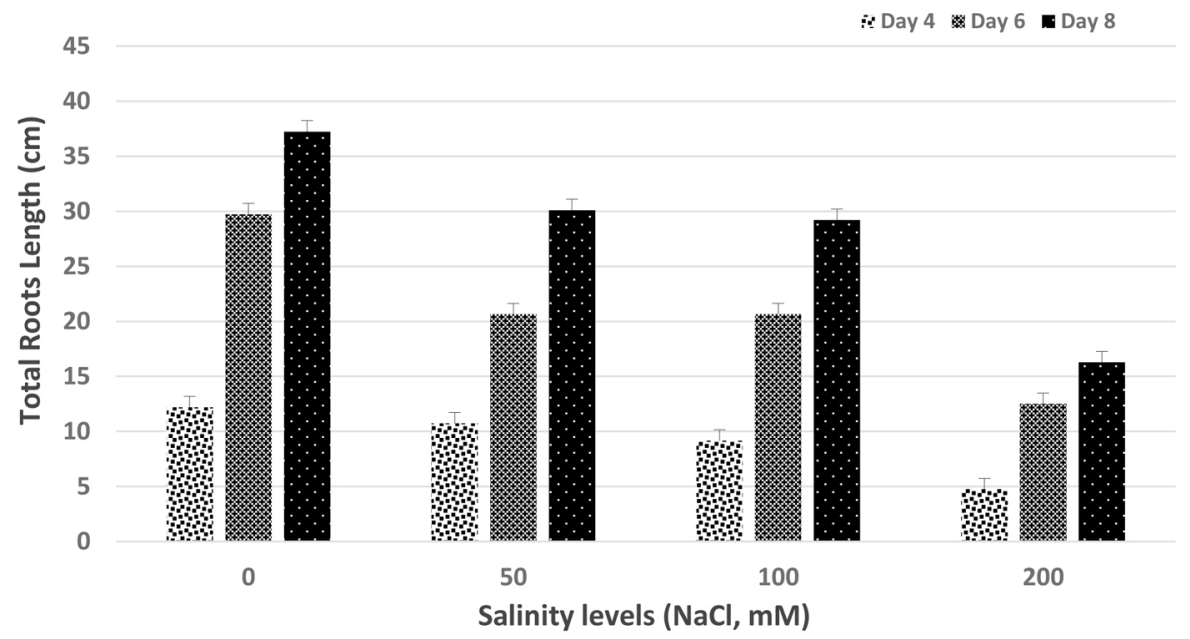

Figure 4. Means of total roots length for barley seeds (H. vulgare L.) under different concentrations of $\mathrm{NaCl}(0,50,100$, and $200 \mathrm{mM})$ during different time interval. Bars represent mean $\pm \mathrm{SE} ; \mathrm{n}=28$ genotypes; 10 seeds/replicate (3 replicates)

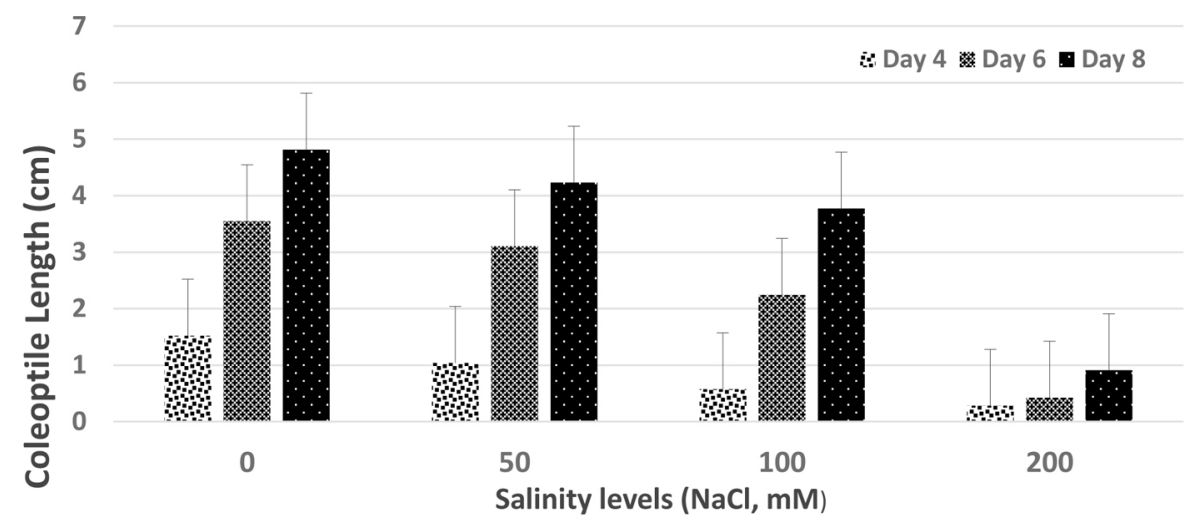

Figure 5. Means of coleoptile length for barley (H. vulgare L.) under different concentrations of $\mathrm{NaCl}(0,50,100$, and $200 \mathrm{mM})$ during different time interval. Bars represent mean $\pm \mathrm{SE} ; \mathrm{n}=28$ genotypes; 10 seeds/replicate (3 replicates) 
(roots number, seminal root number, maximum root number, total roots length and the coleoptile length) were analyzed using ANOVA, i.e. to determine if significant differences were present between salinity and its interaction with exposure time to the salinity stress. The results of these analyses and their significance levels are given in (Table 3).

\section{Effect of genome type (two- and six-rowed genotypes)}

In order to evaluate the influence of various concentration of $\mathrm{NaCl}$ in relation to genome type, one-way and two-way AONVA analysis were performed in order to discover a possible single and combined effects between the salinity and genome type (i.e. two- and six-rowed barley). There was a noticeable responsiveness of germination percentage, and germination rate, of two- and sixrowed barley (Table 4) in agreement with Odat [2018]. Individual genotype, within each group, also differed in their responsiveness. Salinity and exposure were found to be related to genome type (two-way ANOVA, $p \leq 0.001$ ), The genome type (two- and six-rowed) showed significant difference for the effect of salinity and exposure time and their combined interaction. However, it was found that the maximum root length did not differ significantly between genotypes and salinity (Table 4).

\section{DISCUSSION}

The genotypes that have a better performance according to the growth parameters, were M' 1595, M' 1593, Ir 1558, Ir 1631, Ir 1639, Mf 1545 , and Mf 1548 , and according to the physiological parameters were M' 1595 , M' 1580 , M' 1594, Ir 1558, Ir 1553, Ir 1621, Ta 1599, Ta 1572 , $\mathrm{Za} 1560, \mathrm{Za} 1622$ and $\mathrm{Ra}$ 1552. On the other hand, little inhibition in the seedling growth was recorded to the genotypes that have weak growth at germination stage and seedling growth such as (M' 1593, M' 1594, M' 1595, Ir 1558, Ra 1552, Ra 1611, Mf 1616, Mf 1617, Ma 1592).

One of the first and direct effects of salt stress on plants are growth reduction which can be characterized by two phases; the first phase is commonly known as an osmotic effect which is a direct and quick process, and the second phase is a slow process which is caused by the salt toxicity as a consequence of the salt accumulation in plant leaves [Rengasamy, 2002]. In this study, the effects of different $\mathrm{NaCl}$ concentrations on the growth performance of barley were estimated by measuring the germination percentage, root number, root length, seminal root number, total roots length. Exposing barley plants to different $\mathrm{NaCl}$ concentrations along the stress period suppressed their growth, especially at the germination stage. In fact, $200 \mathrm{mM}$ of $\mathrm{NaCl}$ resulted in the most decrease in the germination percentage in Rum, Mutah, and Ra 1611 genotypes. On the other hand, the genotypes Mf 1617, Ta 1572, Ir 1639, Ir 1634, Za 1622 and M' 1595 have a better performance at the germination stage.

Mahmood [2011] reported that the germination percentages in some barley cultivars were decreased in response to the salt stress. Zhang et $a l$. [2010] stated that wheat was negatively affected, by $\mathrm{NaCl}$ due to the decrease of water potential and the ion toxicity. In agreement with other studies, an adverse effect of the salt stress on barley was found and manifested by the reduction in fresh and dry biomass (Kusvuran, 2012). Possibly, these effects of salinity on the barley growth reported in this study are attributed to a decrease in the water potential, specific ion toxicity, and nutrient ion deficiency [Kusvuran, 2012].

Othman et al., studied twelve barley genotypes from Jordan to screen salt tolerance during the germination stage, and the data obtained from the study indicated that the salinity level genotypes interaction effects were observed for seed germination, seed viability and ion uptake. They concluded that the salt stress must be removed from soil surface for successful seedling establishment.

Moreover, Al-Karaki [2001] also studied six barley (Hordeum vulgare L.) cultivars from Jordan such as Rum and AKCAD to screen for any salt tolerance using $\mathrm{NaCl}$, the salt tolerant cultivar lost less $\mathrm{K}^{+}$relative to $\mathrm{Na}^{+}$uptake than did the salt sensitive cultivars. The adverse effects of salt stress on seed germination might result from internal osmotic rather than from ion toxicity effects. Al-Karaki also found that the tolerance of plants to salinity is not a fixed characteristic and may vary with the stage of plant growth. The conclusion drawn based on their study indicated that the final germination percentage and germination rate of all barley cultivars studied decreased with increasing $\mathrm{NaCl}$. 
Saline environments can induce different responses in plants, including re-adjustment of minerals transport and metabolic processes, leading to the growth inhibition [Parida and Das, 2002]. The results of this study revealed a maximum growth reduction at higher levels of salinity (100 and $200 \mathrm{mM} \mathrm{NaCl}$ ). This growth reduction at higher levels of salinity is best explained by a hypersensitivity of barley to saline environments as intercellular accumulation of sodium $\left(\mathrm{Na}^{+}\right)$ is toxic to some extend to cellular metabolism [Greenway and Munns, 1980]. Additionally, high sodium levels disturb potassium $\left(\mathrm{K}^{+}\right)$nutrition and inhibit the production and activity of many important enzymes in the cytoplasm [Demidchik and Tester, 2002].

High $\mathrm{Na}^{+}$accumulation in the cytoplasm can lead to a combination of adverse osmotic impairment, inefficient cellular metabolism, and nutrient imbalance which in turn represent a secondary stress, namely oxidative stress, caused by production of toxic reactive oxygen (ROS) intermediates [Jaleel et al., 2007, Odat 2018]. Exposure of plants to the salinity stress for a long time may decrease their growth, which positively correlated, probably due to the ion toxicity and water deficiency. Moreover, long exposure time to salinity causes ions, i.e. $\mathrm{Na}^{+}$and $\mathrm{Cl}^{-}$, to be taken at high rates, which lead to the uptake suppression of essential minerals [Pessarakli and Touchane, 2006]. In agreement with several reports, the results of this study indicated that the rate of germination is more sensitive to salinity than the overall percent germination, as most likely fast germination ensures rapid seedling establishment [Zia and Khan, 2004].

\section{CONCLUSIONS}

Understanding the changes in cellular levels that occur in response to stress is a key factor towards breeding better crops under stress. This study concluded that salinity had negative effects on the germination and vegetative growth of all Jordanian barley genotypes grown in petri-dishes under controlled environmental conditions.

\section{Acknowledgement}

We acknowledge Al-Balqa Applied University for its financial support.

\section{REFERENCES}

1. Abdel-Ghani A.H. 2009. Response of wheat varieties from semi-arid of Jordan to salt stress. Journal of Agronomy and Crop Science, 195, 55-65.

2. Al Karaki G. 2001. Germination, sodium, and potassium concentrations of barley seeds as influenced by salinity. Journal of Plant Nutrition, 24, 511-522.

3. Ansari O., Azadi M.S., Sharif-Zadeh F., Younesi E. 2013. Effect of Hormone Priming on Germination Characteristics and Enzyme Activity of Mountain Rye (Secale montanum) Seeds under Drought Stress Conditions. Journal of Stress Physiology \& Biochemistry, 9, 61-71.

4. Anwar S., Safi M., Jan M. 2011 Response of barley genotypes to salinity stress as alleviated by seed priming. Pakistan Journal of Botany, 43, 2687-2691.

5. Ashraf M., Foolad M. 2007. Roles of Glycine Betaine and Proline in Improving Plant Abiotic Stress Resistance. Environmental and Experimental Botany, 59, 206-216.

6. Briggs, D.E. (1978). Barley. Chapman and Hall Ltd, London.

7. Demidchik V., Tester M. 2002. Sodium fluxes through non-selective cation channels in the plasma membrane of protoplasts from Arabidopsis thaliana roots. Plant Physiology, 128, 379-387.

8. Flowers T.J., Yeo A.R. 1995. Breeding for salinity resistance in crop plants-where next? Australian Journal of Plant Physiology, 22, 875-884.

9. Greenway H., and Munns, R. 1980. Mechanisms of salt tolerance in nonhalophytes. Annual Review of Plant Physiology, 31, 149-190.

10. Hasanuzzaman M., Nahar K., Alam M.M., Roychodhury R., Fujita M. 2013. Physiological, Biochemical, and Molecular Mechanisms of Heat Stress Tolerance in Plants. Internationa Journal of Molecular Sciences, 14, 9643-9684.

11. Jaleel C.A, Manivannan P., Sankar B et al. 2007 Water deficit stress mitigation by calcium chloride in Catharanthus roseus: Effects on oxidative stress, proline metabolism and indole alkaloid accumulation. Colloids Surf. B: Biointerfaces, 60, 110-116.

12. Mahmood K. (2011) Salinity tolerance in barley (hordeum vulgare 1.): Effects of varying $\mathrm{NaCL}, \mathrm{K}$ $+/ \mathrm{Na}+$ and NaHCO 3 levels on cultivars differing in tolerance. Pakistan Journal of Botany, 43, 1651-1654.

13. Mekhaldi A., Benkhelifa M., Belkhodja M. 2008. The effects of salinity on gaz exchange on different developmental stages of Mung Bean (Vigna radiata L. Wilczek). International Journal of Botany, 4: 269-275.

14. Odat N., Hasan M.K., Obeidat M.S., Shatnawi M.A., Abu-Romman S.M., Qrunfleh I.M., Massadeh M. I. 
2015. Identifying Selection Signatures Related to Domestication Process in Barley (Hordeum vulgare L.) Landraces of Jordan Using Microsatellite Markers. Jordan Journal of Biological Sciences, 8, 307-313.

15. Odat N. 2018. Molecular and biochemical responses of barley (Hordeum vulgare L.) to $\mathrm{NaCl}$ salinity stress and salicylic acid. Research on Crops, 19, 101-106.

16. Parida A.K., Das A.B., Das P. 2002. NaCl stress causes changes in photosynthetic pigments, proteins and other metabolic components in the leaves of a true mangrove, Bruguiera parviflora, in hydroponic cultures. Journal of Plant Biolology, 45, 28-36.

17. Passioura J.B. 2007. The drought environment: physical, biological and agricultural perspectives. Journal of Experimental Botany, 58, 113-7.

18. Patade V.Y., Maya K., Zakwan A. 2011. Seed priming mediated germination improvement and tolerance to subsequent exposure to cold and salt stress in capsicum. Research Journal of Seed Sciences, 4, 125-36.

19. Pessarakli, M. \& Touchane, H. 2006 Growth responses of bermudagrass and seashore paspalum under various levels of sodium chloride stress Journal of Food, Agriculture \& Environment, 4, 240-243.

20. Qiu L., Wu D., Ali S., Cai S., Dai F., Jin X. Wu F., Zhang G. 2011. Evaluation of salinity tolerance and analysis of allelic function of HvHKT1 and HvHKT2 in Tibetan wild barley. Theoretical and Applied Genetics, 122, 695-703.

21. Rengasamy P. 2002. Transient salinity and subsoil constraints to dryland farming in Australian sodic soils: an overview. Australian Journal of Experimental Agriculture 42(3), 351-361

22. Shrivastava P., Kumar R., 2015. Soil salinity: A serious environmental issue and plant growth promoting bacteria as one of the tools for its alleviation. Saudi Journal of Biological Sciences, 22, 123-131.

23. Yadav S., Irfan M., Ahmad A. 2011. Causes of salinity and plant manifestations to salt stress: A review. Journal of Environmental Biology, 32(5), 667-85

24. Zhang H, Tan Z.Q., Hu L.Y., Wang S.H., Luo J.P., Jones R.L. 2010. Hydrogen sulfide alleviates aluminum toxicity in germinating wheat seedlings. Journal of Integrative Plant Biology, 52, 556-567.

25. Zia S., Khan M.A. 2004. Effect of light, salinity and temperature on seed germination and Limonium stocksii Canadian Journal of Botany, 82, 151-157. 